\title{
Reaction of Portland Cement with Carbon Dioxide
}

\author{
Charles M. Hunt, Vernon Dantzler, Lewis A. Tomes, ${ }^{1}$ and Raymond L. Blaine
}

The reaction of portland cement with carbon dioxide was found to be greatly influenced by the moisture environment of the cement. Reaction with carbon dioxide and water also affected the subsequent hydration of the cement.

\section{Introduction}

Portland cements stored for several months in an environment that permits gradual access to air sometimes appear to hydrate more slowly than when the cements were first tested. It is a well-known fact that cement can react with carbon dioxide when exposed to air or other atmospheres containing this gas [1]. ${ }^{2} \quad$ The reaction is accompanied by a certain amount of hydration due to atmospheric moisture. A number of years ago Bonnell [2] studied the effect of carbonation of cement on setting time, heat of hydration, and tensile strength of the material after hydration. He found all of these properties to be influenced by carbonation of the original cement.

More recently, the determination of nonevaporable water in hardened cement pastes has been used rather extensively to estimate the degree of hydration of cement $[3,4,5,6]$. The present paper considers the effect of carbonation of cement upon its subsequent hydration, using nonevaporable water as a measure of hydration.

Bonnell [2] and Lea [1] have mentioned that the reaction of cement with carbon dioxide is dependent upon relative humidity and that such reaction will not take place in a dry atmosphere. A brief reinvestigation of this matter is also described in this paper.

\section{Methods and Materials}

\subsection{Carbon Dioxide Exposure}

Cement was exposed to carbon dioxide in a tube similar to the one illustrated in figure 1 . The carbon dioxide was brought to predesired relative humidity by passing it through gas-washing bottles containing sulfuric acid of appropriate concentration. Approximately $1 \mathrm{~g}$ of cement was taken for each exposure and the entire specimen analyzed. When larger amounts of cement were exposed, the cement was taken out and blended at intervals.

Cement was also carbonated in air by exposure in a large outdoor enclosure where it could have free access to air but be protected from wind and rain. The cement was spread in layers $2 \mathrm{~mm}$ thick or less for this type of exposure.

1 Research Associate at the National Bureau of Standards, representing the Calcium Chloride Institute.

2 Figures in brackets indicate the literature references at the end of this paper.

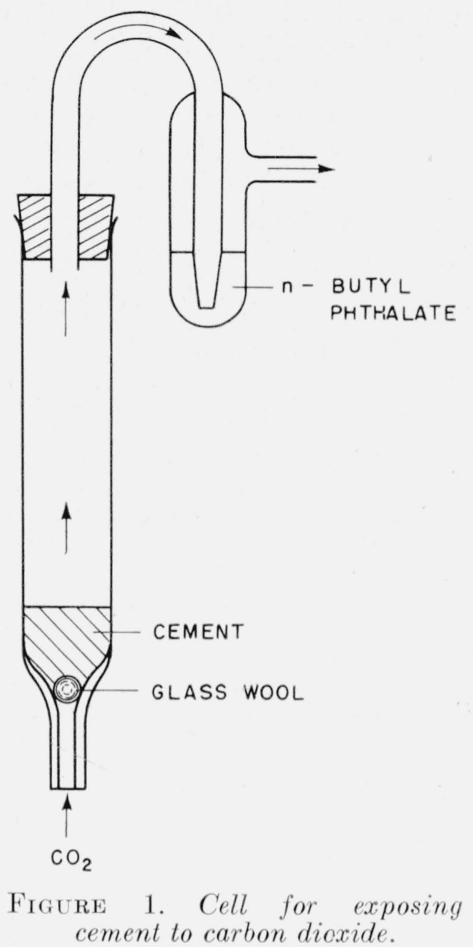

\subsection{Determination of Carbon Dioxide}

The carbon dioxide content of the cement was determined by the evolution method, digesting the material with $4 N$ hydrochloric acid and absorbing the evolved carbon dioxide in Ascarite. Anhydrous calcium chloride was used in the system to absorb water, and silver sulfate in concentrated sulfuric acid was used to absorb any hydrogen sulfide that might be present. The apparatus and other details of the determination are similar to those described by Kolthoff and Sandell [7].

\subsection{Hydration of Cement}

The cement was mixed with water in a watercement ratio of 0.5 . Mixing was carried out in a soil-density balloon ${ }^{3}$ to minimize contact with air.

${ }^{3}$ Soil-density ballons are supplied by the Rainhart Co., Austin, Tex. The type used in this work had a total volume of about $160 \mathrm{ml}$. 
The paste was cast in the form of $1 / 2-i n$. cylinders by extrusion into paraffin-coated paper molds. The paste-filled molds were kept in stoppered glass tubes for $24 \mathrm{hr}$, after which the specimens were sawed into $1 / 2$-in. sections. Hydration for periods greater than $24 \mathrm{hr}$ was carried out in paraffin-sealed quart jars in the presence of a high concentration of water vapor.

\subsection{Determination of Nonevaporable Water}

The pastes were crushed and nonevaporable water was determined by a procedure similar to that described by Copeland and Hayes [5]. However, instead of applying a correction for ignition loss of the original cement, the specimens were analyzed for carbon dioxide and corrected for carbon dioxide content. Nonevaporable water computed in this way includes all nonevaporable water in the specimen, regardless of whether it was acquired before or after mixing.

\subsection{Cements}

Four cements were used in these experiments. All were type I cements according to Federal Specification SS-C-192a. The results of chemical analysis of the cements are given in table 1 .

TABLE 1. Chemical composition of cements

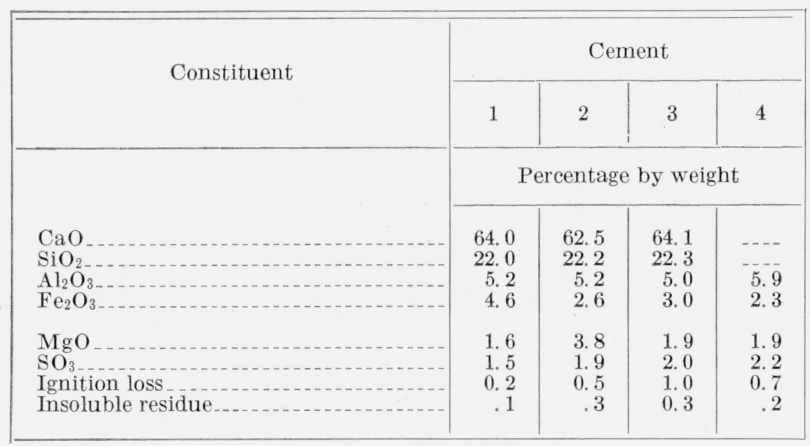

\section{Results}

\subsection{Effect of Water on the Rate of Carbonation}

Portland cement was exposed to carbon dioxide at different relative humidities for different periods of time and analyzed after exposure. In figure 2 the carbon dioxide content is plotted as a function of exposure time. At relative humidities of less than 25 percent, carbonation was found to be very slow. The slope of the bottom curve in figure 2 suggests that the cement would not have reacted with much more carbon dioxide even if it were exposed for a much longer period. At 50 to 55 percent, the rate of carbonation increased, and at 90- to 95-percent relative humidity the increase was most marked. The curves at these higher relative humidities showed no evidence of leveling off after a week of exposure.

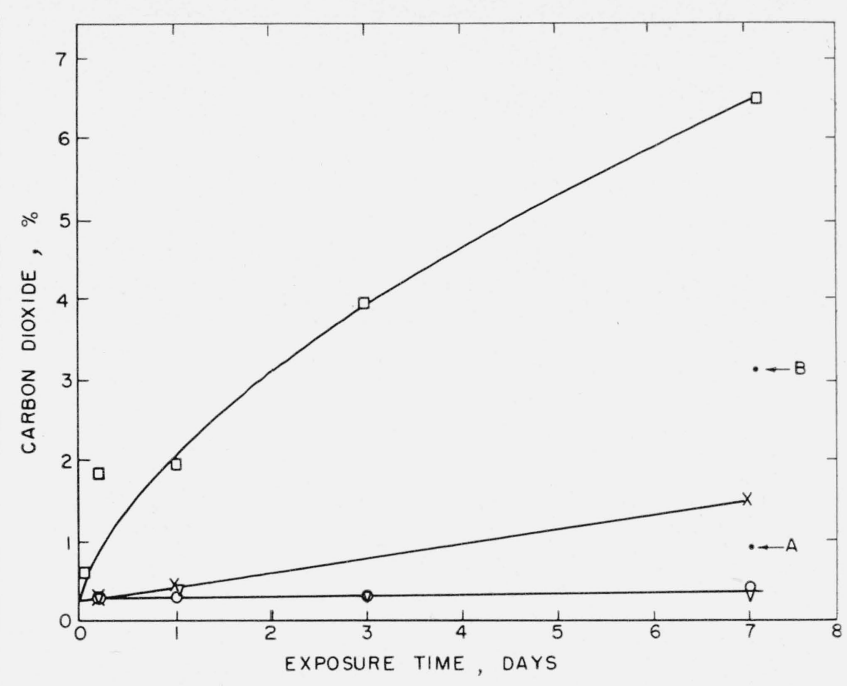

FIGURE 2. Effect of relative humidity on the rate of carbonation of portland cement.

$\nabla$, Cement exposed to dry carbon dioxide, $\bigcirc$, cement exposed to carbon dioxide at 20 - to 25-percent relative humidity, $X$, cement expcsed to carbon dioxide at 50 - to 55-percent relative humidity, $\square$, cement exposed to carbon dioxide at 90 to 95-percent relative humidity, A, cement exposed to air for 1 week, B, fresh cement paste exposed to air for 1 week.

Because the rate of carbonation was so dependent on relative humidity, cement was also exposed by passing carbon dioxide into a freshly-mixed paste. The initial water-cement ratio of the paste was 0.5 , but the mixture dried during exposure. In figure 3 the rate of carbonation of fresh paste is compared with that of cement at 90 - to 95 -percent relative humidity. It may be seen that during the first few hours the paste carbonated much faster than the cement, but thereafter the rate diminished sharply. The decrease in rate was probably due to drying of the paste. It is clear from the results in figure 2 and 3 that water is an important limiting factor in the rate of carbonation of cement.

Cement, and fresh cement paste, were also exposed to air. Figure 4 shows the amount of carbon dioxide gained upon exposure to air for periods up to 28 days. Again the fresh paste acquired much more carbon dioxide than the dry cement during the first day, but, after drying, the rate for paste was slightly less than that of the cement. From these results it is clear that even at the low carbon dioxide concentrations normally present in air, water can also be a ratedetermining factor.

Point A, in figure 2, shows the amount of carbon dioxide in the cement after a week of exposure to air. It is included in the figure to point out that the cement contained more carbon dioxide after a week in air than in pure, dry carbon dioxide. Point B, in figure 2, shows that the cement paste contained more carbon dioxide after a week's exposure to air than was present in dry cement after a similar period in carbon dioxide at 50 - to 55 -percent relative humidity. From these observations it is concluded that the concentration of water can exert a greater effect on the rate of carbonation than the carbon dioxide concentration. 


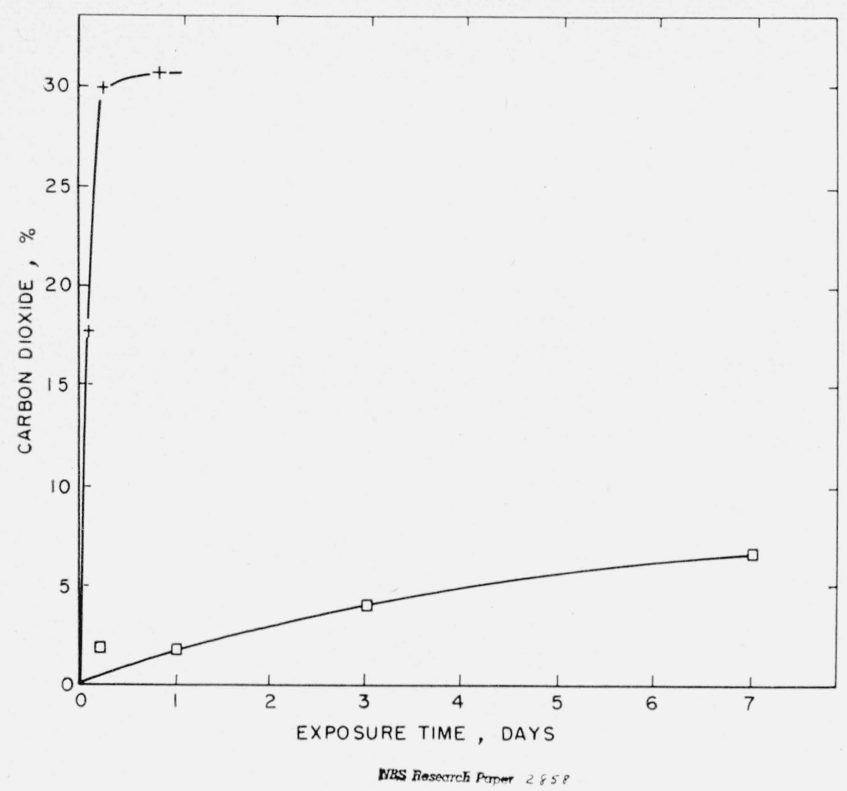

FIgURE 3. Rate of carbonation of cement and fresh cement paste in carbon dioxide.

$\square$, Cement exposed to carbon dioxide at 90- 95-percent relative humidity; + , fresh cement paste exposed to dry carbon dioxide.
The results shown in figures 2,3 , and 4 were all obtained with cement 1 in table 1 .

\subsection{Effect of Carbonization on the Hydration of Cement}

Cements containing different amounts of carbon dioxide were mixed with water and allowed to hydrate. Nonevaporable water in the hardened paste was determined after 1 day, 7 days, and 28 days of hydration. The results are given in table 2 . It may be seen that the more highly carbonated cements contained smaller amounts of nonevaporable water after hydration. In figures 5,6 , and 7 , carbon dioxide content of the cement before mixing is plotted as a function of nonevaporable-water content of the hardened paste after hydration. Both quantities have been expressed in millimoles per $100 \mathrm{~g}$ of ignited cement. This comparison shows no simple stoichiometric relationship between the increase in carbon dioxide content of the cement and the decrease in nonevaporable water in the paste, but it shows that comparatively small differences in the number of millimoles of carbon dioxide in the cement are associated with rather large differences in the number of millimoles of nonevaporable water. The effect is just as evident after 28 days of hydration as after the first day.

Carbonation of cement is accompanied by a certain amount of hydration by water vapor in the carbonating atmosphere. For this reason, the effects shown in table 2 and in figures 5, 6, and 7 may

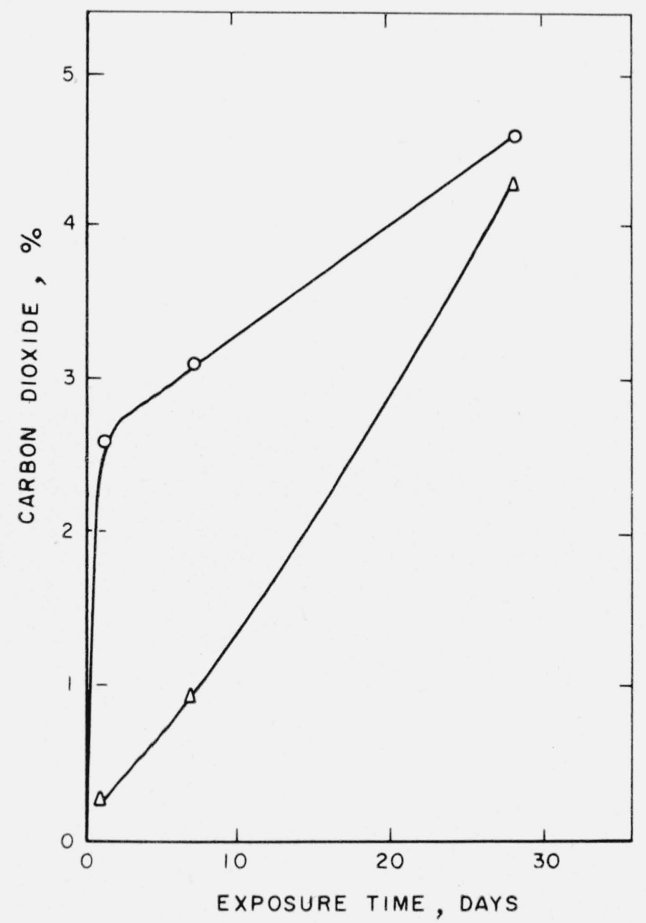

FiguRE 4. Rate of carbonation of cement and fresh cement paste in air.

$\triangle$, Cement exposed to air, $\bigcirc$, fresh cement paste exposed to air.

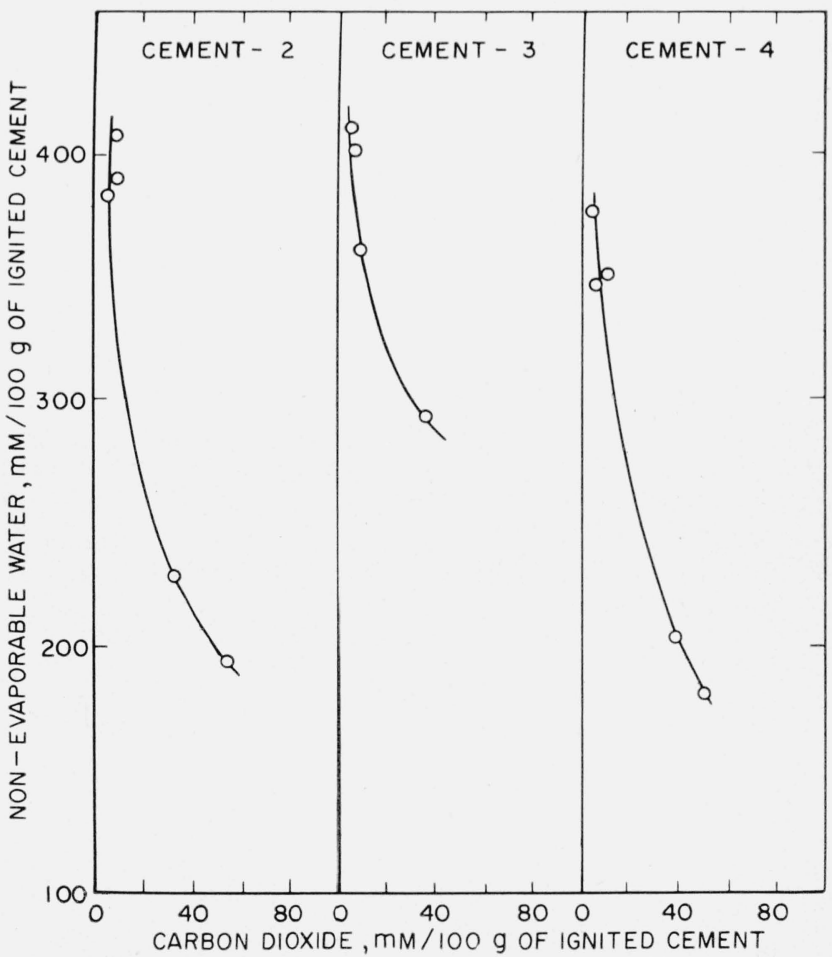

Figure 5. Nonevaporable water content of cement pastes after 1 day of hydration as a function of carbon dioxide content of the cement before mixing. 


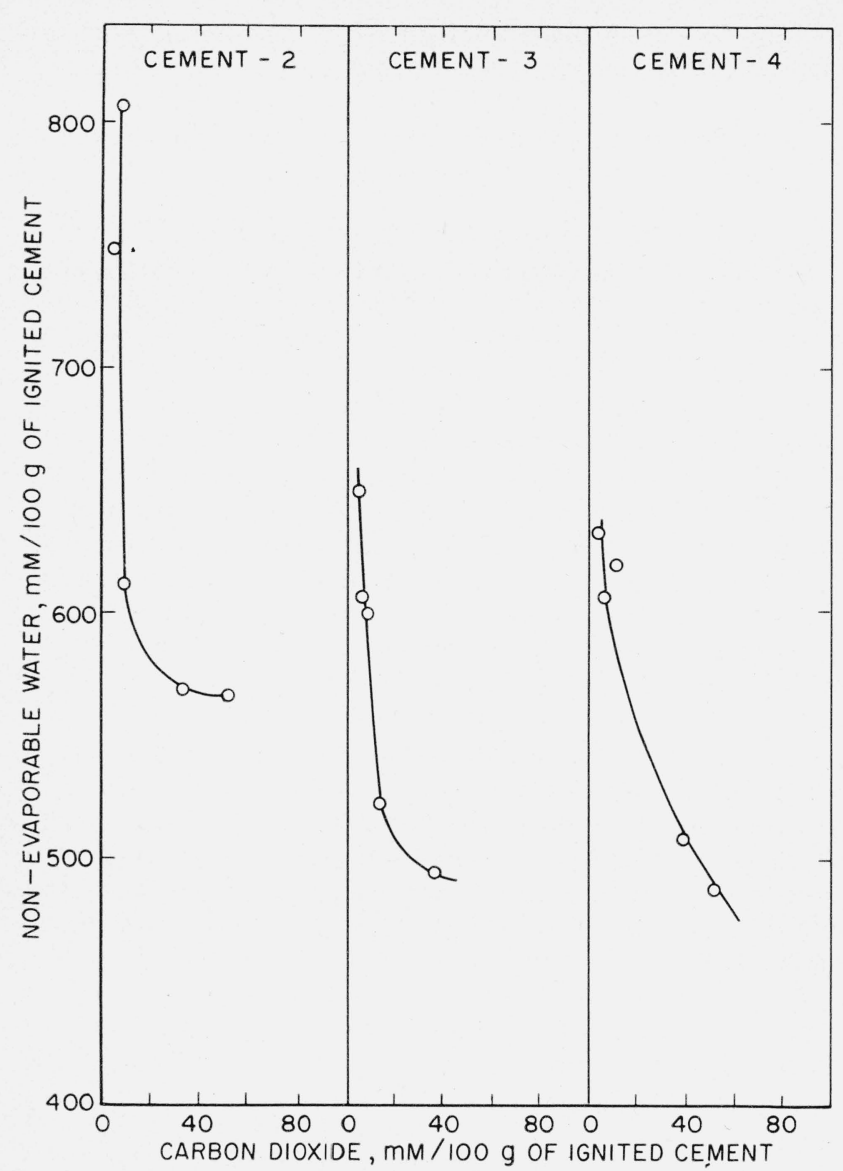

Figure 6. Nonevaporable water content of cement pastes after $\%$ days of hydration as a function of carbon dioxide content of the cement before mixing.

TABLE 2. Nonevaporable water content of hardened pastes and carbon dioxide content of cement from which they were prepared

\begin{tabular}{|c|c|c|c|c|}
\hline \multirow{3}{*}{ Cement } & \multirow{3}{*}{$\begin{array}{c}\text { Initial } \mathrm{CO}_{2} \\
\text { (percentage } \\
\text { of ignited } \\
\text { cement) }\end{array}$} & \multicolumn{3}{|c|}{ Nonevaporable water } \\
\hline & & $\begin{array}{c}\text { 1-day } \\
\text { hydration }\end{array}$ & $\begin{array}{c}1 \text {-week } \\
\text { hydration }\end{array}$ & $\begin{array}{l}\text { 1-month } \\
\text { hydration }\end{array}$ \\
\hline & & \multicolumn{3}{|c|}{ Percentage of ignited cement } \\
\hline 2 & $\begin{array}{r}0.39 \\
.19 \\
.41 \\
1.48 \\
2.46\end{array}$ & $\begin{array}{l}7.35 \\
6.91 \\
7.04 \\
4.11 \\
3.49\end{array}$ & $\begin{array}{l}14.50 \\
13.47 \\
11.01 \\
10.22 \\
10.19\end{array}$ & $\begin{array}{l}18.05 \\
16.95 \\
17.30 \\
15.15 \\
14.89\end{array}$ \\
\hline $3 \ldots$ & $\begin{array}{r}0.25 \\
.27 \\
.36 \\
.64 \\
1.68\end{array}$ & $\begin{array}{l}7.40 \\
7.25 \\
6.52 \\
5.28\end{array}$ & $\begin{array}{r}11.70 \\
10.93 \\
10.80 \\
9.40 \\
8.91\end{array}$ & $\begin{array}{l}15.40 \\
14.38 \\
14.20 \\
14.16 \\
13.34\end{array}$ \\
\hline $4 \ldots$ & $\begin{array}{r}0.23 \\
.28 \\
.52 \\
1.75 \\
2.31\end{array}$ & $\begin{array}{l}6.78 \\
6.22 \\
6.38 \\
3.65 \\
3.27\end{array}$ & $\begin{array}{r}11.46 \\
10.91 \\
10.98 \\
9.14 \\
8.79\end{array}$ & $\begin{array}{l}19.47 \\
17.75 \\
18.42 \\
15.60 \\
16.22\end{array}$ \\
\hline
\end{tabular}

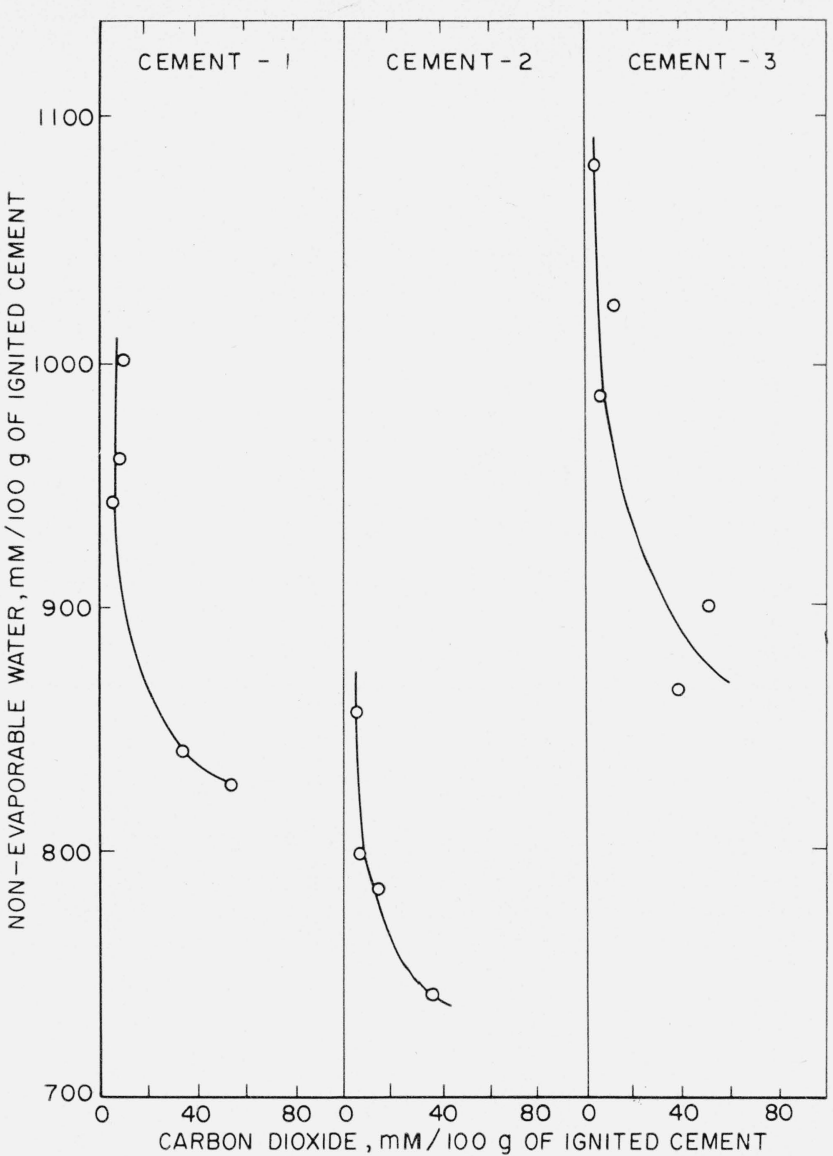

Figure 7. Nonevaporable water content of cement pastes after 28 days of hydration as a function of carbon dioxide content of the cement before mixing.

not be exclusively due to carbon dioxide in the cement. Pastes were prepared from four specimens of cement in which the initial water content of the original cement varied from specimen to specimen, whereas the carbon dioxide content was nearly constant. These were compared with pastes from four specimens in which both carbon dioxide and water contents of the original cement varied from specimen to specimen. The nonevaporable water content of the eight pastes after $24 \mathrm{hr}$ of hydration are given in table 3 , along with the water and carbon dioxide contents of the original cement. It is evident that both the water and carbon dioxide in the original cement exerted an influence on subsequent hydration. The comparative effects of the water and carbon dioxide in the original cement can perhaps be best illustrated by considering nonevaporable water content of the hydrated paste as a function of the water content of the original cement, as has been done in figure 8 . It may be seen from the figure that carbon dioxide produced an effect on hydration over and above that produced by water in the original cement. The decrease in millimoles of nonevaporable water in the paste was also somewhat greater than the total number of millimoles of carbon dioxide and water in the cement that were associated with the effect. 
TABLE 3. Nonevaporable water content of hardened cement pastes and carbon dioxide and water content of cement from which they were prepared

\begin{tabular}{|c|c|c|c|}
\hline Cement & $\begin{array}{l}\text { Initial } \mathrm{CO}_{2} \\
\text { (percentage } \\
\text { of ignited } \\
\text { cement) }\end{array}$ & $\begin{array}{l}\text { Initial } \mathrm{H}_{2} \mathrm{O} \\
\text { (percentage } \\
\text { of ignited } \\
\text { cement) }\end{array}$ & $\begin{array}{c}\text { Nonevaporable } \\
\text { water after } 1 \\
\text { day (percentage } \\
\text { of ignited } \\
\text { cement) }\end{array}$ \\
\hline 2 & $\begin{array}{l}0.44 \\
.65 \\
1.80 \\
2.76\end{array}$ & $\begin{array}{r}0.97 \\
1.00 \\
1.19 \\
1.55\end{array}$ & $\begin{array}{l}\text { 6. } 79 \\
5.52 \\
\text { 2. } 96 \\
2.25\end{array}$ \\
\hline $2 \ldots$ & $\begin{array}{r}0.43 \\
.48 \\
.49 \\
.49\end{array}$ & $\begin{array}{l}0.74 \\
.89 \\
1.53 \\
1.36\end{array}$ & $\begin{array}{l}7.08 \\
6.81 \\
5.55 \\
5.49\end{array}$ \\
\hline
\end{tabular}

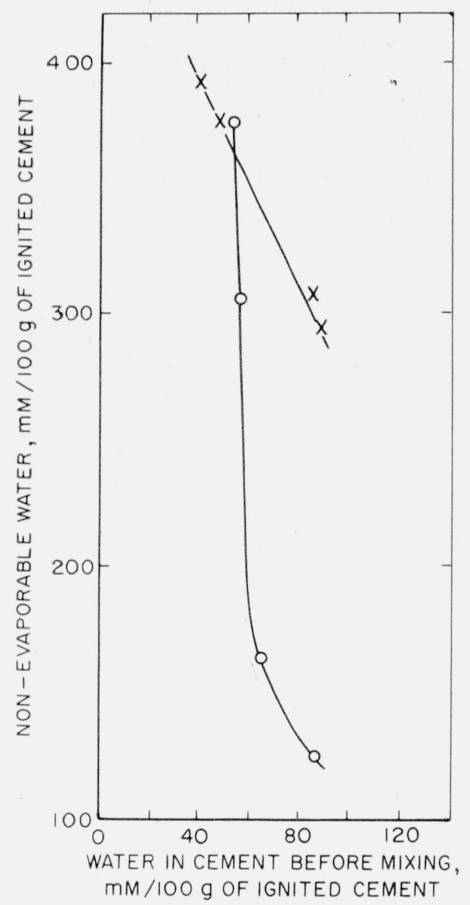

Figure 8. Nonevaporable water content of cement pastes as a function of the water in the cement before mixing.

$\times, 0.43$ - to 0.49 -percent $\mathrm{CO}_{2}$ in cement' , 0.44 - to 2.76-percent of $\mathrm{CO}_{2}$ in cement.

\section{Discussion}

The results in figure 2 are in essential agreement with the statements of Bonnell [2] and Lea [1] relating to the effect of relative humidity on the reaction of carbon dioxide with cement. A certain amount of water is necessary before carbonation can proceed, at least at any appreciable rate.

The results in figures 3 and 4 show that cement in a fresh paste is particularly susceptible to carbonation wherever the surface is exposed. This observation is of interest in connection with Kauer and Freeman's [8] investigation into the cause of softness of the surface of concrete floors where oil-burning heaters were used to keep the freshly placed concrete warm. They attributed this undesirable behavior to carbonation. The results in figures 2 and 3 , although they give no direct evidence as to the quality of the cement after carbonation, show that the exposed surface of a freshly mixed cement will react with carbon dioxide many times as fast during the first few hours as will the same cement before mixing.

It is also evident from the results in figures 5,6 , and 7 that the amount of nonevaporable water in a hydrated cement after a given time of hydration is influenced to a measurable extent by the amount of carbon dioxide in the original cement before mixing. It is interesting to consider these results in the light of Bonnell's [2] observation that the tensile strength of mortars and pastes at early ages was adversely affected by small amounts of carbon dioxide in the original cement, whereas strength at 28 days was not adversely affected until carbon dioxide levels greater than those in the present experiments were encountered. If any comparison between the present observations and those of Bonnell is justified, it implies that cement containing different amounts of carbon dioxide can develop the same strength at 28 days, even though there may be measureable differences in the amount of hydration products present.

The mechanism by which carbonation and reaction with atmospheric moisture reduces subsequent hydration is not established. The similarity of the effect at all ages, as shown in figures 5, 6, and 7, suggests that changes produced during carbonation do not affect the rate of hydration, as such, unless possibly within the first few hours. However, as a result of carbonation, a fraction of the cement is made unavailable for hydration, and the amount of hydratable material so affected is not a linear function of carbon dioxide content.

From the standpoint of practical use it is doubtful if small amounts of carbon dioxide and water seriously impair the hydraulic properties of portland cement. All cement probably contains small amounts of these substances. In the experiments described here, cement was given maximum opportunity to come into contact with carbon dioxide and water, whereas in bulk storage the cement in the outer layers of the mass affords some protection to the cement on the interior. However, to obtain maximum reproducibility in carefully controlled hydration studies, it is desirable to avoid reaction with carbon dioxide and water during storage.

\section{Summary}

In confirmation of earlier observations reported. by Bonnell [2] and Lea [1], cement was found to carbonate slowly or not at all when exposed to pure, dry carbon dioxide. In the presence of increasing concentrations of water vapor, however, the rate of carbonation increased rapidly. Cement was also found to carbonate faster when freshly mixed with water than in an atmosphere of high relative humidity. 
The amount of nonevaporable water in a hardened cement after 1 day, 7 days, or 28 days of hydration was found to be smaller as the amount of carbon dioxide in the original cement increased. The reduction in the amount of hydration at any given age was greater than the amount of carbon dioxide associated with the effect, when both were compared on a molecular basis. Water in the original cement also appeared to curtail subsequent hydration of the cement, but the effect was less than the combined effect of water and carbon dioxide.

Washington, November 13, 1957.

\section{References}

[1] F. M. Lea, The chemistry of cement and concrete, p. 250 (St. Martins Press, New York, N. Y., 1956).

[2] D. G. R. Bonnell, Dept. Scientific and Industrial Research, Building Research Tech. Paper No. 19 (His Majesty's Stationery Office, 1936).

[3] T. C. Powers and T. L. Brownyard, Studies in the physical properties of portland cement paste, Part 2, studies of water fixation, Proc. Am. Concrete Inst. 43, 249 (1946); Also included in Portland Cement Assoc. Bul. 22.

[4] T. C. Powers, Non-evaporable water content of hardened portland cement paste-its significance for concrete research and its methcd of determination, ASTM Bul. No. 158 (May 1949); also published as Portland Cement Assoc. Bul. No. 29.

[5] L. E. Copeland and J. C. Hayes, Determination of nonevaporable water in hardened portland cement paste, ASTM Bul. No. 194, p. 70 (1953); also published as Portland Cement Assoc. Bul. No. 47.

[6] L. E. Copeland and R. H. Bragg, Self desiccation in portland cement pastes, ASTM Bul. No. 204, p. 34 (1955); also published as Portland Cement Assoc. Bul. No. 52.

[7] I. M. Kolthoff and E. B. Sandell, p. 373 (The MacMillan Co., New York, N. Y., 1952).

[8] J. A. Kauer and R. L. Freeman, Proc. Am. Concrete Inst. 52, 447 (1955). 